\title{
Hand-Carried and High-End Ultrasound Systems are Equally Inferior to Abdominal Radiography and Multidetector Computed Tomography in the Diagnosis of Pneumoperitoneum
}

\author{
Tragbare und high-end Ultraschallsysteme sind in der Diagnose des \\ Pneumoperitoneum gleichermaßen der Abdomenübersichtsaufnahme \\ und der Multidetektor-Computertomografie unterlegen
}

Authors

Affiliation
S. Schleder, E. M. Jung, P. Heiss, C. Stroszczynski, A. G. Schreyer

Department of Radiology, University Medical Center Regensburg
Key words

- abdomen

- ultrasound

- conventional radiography

- CT

received $\quad 15.7 .2013$

accepted $\quad 4.11 .2013$

Bibliography

Dol http://dx.doi.org/

10.1055/s-0033-1356222

Published online: 29.1.2014

Fortschr Röntgenstr 2014; 186 :

219-224 @ Georg Thieme

Verlag KG Stuttgart · New York . ISSN 1438-9029

\section{Correspondence}

Dr. Stephan Schleder

Universitätsklinikum

Regensburg, Institut für

Röntgendiagnostik

Franz-Josef-Strauß-Allee 11

93053 Regensburg

Germany

Tel.: ++49/0941/9447401

Fax: ++49/0941/9447402

Stephan.Schleder@ukr.de

\section{Zusammenfassung \\ $\nabla$}

Ziel: Das Pneumoperitoneum (PP) stellt ein schwerwiegendes Krankheitsbild dar. Eine schnelle und korrekte Diagnose ist für die weitere Therapie unumgänglich. Ziel dieser Studie war es, die Wertigkeit eines modernen tragbaren Ultraschallgerätes (HCU) im Vergleich zu einem high-end Ultraschallsystem (HUS) anhand der Diagnose PP bei Patienten mit akutem abdominellem Schmerz zu evaluieren.

Material und Methoden: 31 Patienten mit akutem abdominellem Schmerz wurden unabhängig von ihrer Grunderkrankung in die Studie eingeschlossen und mittels HCU und HUS untersucht. Goldstandard für die Diagnose PP waren die Ergebnisse der Multidetektor-Computertomografie (MDCT) und der konventionellen Abdomenübersichtsaufnahme (AR). Die Studie wurde von zwei erfahrenen Untersuchern in Unkenntnis der Ergebnisse der MDCT und der AR durchgeführt.

Ergebnisse: Bei fünf (16\%) Patienten wurde mittels MDCT und AR das Vorliegen eines PP diagnostiziert. HCU zeigte eine Sensitivität und Spezifität von $80 \%$ bzw. $81 \%$. HUS zeigte eine Sensitivität und Spezifität von $80 \%$ bzw. $89 \%$. Zwischen HCU und HUS bestand kein statistisch signifikanter Unterschied in der Diagnosefindung bezüglich PP. Schlussfolgerung: Das Vorliegen eines PP kann mittels HCU und HUS mit annähernd gleicher Genauigkeit aufgedeckt werden, jedoch sind beide Modalitäten der MDCT bzw. dem AR unterlegen. Jedoch stellen HCU und HUS wertvolle kostengünstige Untersuchungen ohne die Notwendigkeit einer Strahlenexposition dar, die es ermöglichen Rückschlüsse auf das Vorliegen eines PP zu ziehen und die Notwendigkeit weiterer Untersuchungen zu erkennen.

Kernaussagen:

1. Das Pneumoperitoneum (PP) ist eine schwerwiegende Diagnose.

\section{Abstract \\ $\nabla$}

Purpose: Pneumoperitoneum (PP) is a severe finding in emergency departments. Its quick and correct diagnosis is indispensable for the further treatment of patients. The aim of this study was to analyze the clinical value of abdominal ultrasound performed with a modern hand-carried ultrasound (HCU) device as well as with a high-end ultrasound (HUS) system in the diagnosis of PP in patients with acute abdominal pain.

Materials and Methods: 31 patients with acute abdominal pain were enrolled in this study irrespective of their underlying disease, and examination with a latest generation HCU and a newest generation HUS was performed. Diagnosis of PP was based on findings of multidetector computed tomography (MDCT) and abdominal radiography (AR) as the standard of reference. The study was carried out by two independent and experienced examiners unaware of the diagnosis made by MDCT or AR.

Results: In five (16\%) patients PP was identified by MDCT and AR. Examination with HCU was calculated with a sensitivity and specificity of $80 \%$ and $81 \%$, respectively. Examination with HUS yielded a sensitivity and specificity of $80 \%$ and $89 \%$, respectively.

Conclusion: PP can be detected by HCU and HUS with almost equal accuracy in patients with acute abdominal pain but both methods are inferior compared to MDCT and AR. However, HCU and HUS can accelerate the triage of patients and help to make decisions regarding the necessity of further examinations without the need for radiation and while reducing economic and logistic resources.

Key Points:

1. Pneumoperitoneum (PP) is a severe finding in emergency departments. 
2. Tragbarer (HCU) und high-end (HUS) Ultraschall können helfen ein PP zu erkennen.

3. Abdomenübersichtsaufnahme (AR) und Multidetektor-Computertomografie (MDCT) sind in der Diagnose des PP überlegen.

4. HCU und HUS beschleunigen die Versorgung des Patienten.

5. HCU und HUS können die Entscheidung bezüglich weiterer Untersuchungen erleichtern.
2. Hand-carried (HCU) and high-end (HUS) ultrasound systems can be helpful in detecting PP.

3. Abdominal radiography (AR) and multidetector computed tomography (MDCT) are superior in detecting PP.

4. HCU and HUS can accelerate the triage of patients.

5. HCU and HUS can be helpful when making decisions regarding the necessity of further examinations.

Citation Format:

- Schleder S, Jung EM, Heiss P et al. Hand-Carried and High-End Ultrasound Systems Are Equally Inferior to Abdominal Radiography and Multidetector Computed Tomography in the Diagnosis of Pneumoperitoneum. Fortschr Röntgenstr 2014; 186: 219-224

\section{Introduction}

$\nabla$

Free intra-abdominal air, referred as pneumoperitoneum (PP), represents a critical radiological appearance in severely ill patients. In patients presenting with an acute onset of abdominal pain without any major abdominal surgery immediately before the onset, PP as an indirect sign of gastrointestinal perforation has to be excluded. The most sensitive radiological method for the diagnosis of small amounts of PP is usually computed tomography [1]. Still posterior-anterior chest and erect abdominal radiographs are commonly used alternatives for the daily clinical workflow resulting in fast imaging results and therefore fast diagnosis in these critically ill patients [2, 3]. Even small amounts of as little as $1 \mathrm{ml}$ of free intra-abdominal air space can be recognized with these modalities $[2,4]$. However, due to the patient's condition, upright radiographs cannot always be obtained. In these cases, left-lateral decubitus abdominal radiography seems to be the best alternative with comparable findings $[5,6]$.

Nevertheless, ultrasound is the first chosen imaging modality in patients with acute abdominal pain in most emergency departments because it represents a reliable, inexpensive and therefore economical examination which can easily be performed in the examination room without the need to transport the patient [7-13]. Additionally, ultrasound examination can frequently provide an immediate diagnosis for several queries such as intra-abdominal fluid collection as an indicator of hemorrhage or peritonitis. Furthermore, the whole abdomen can be probed during one examination without radiation exposure $[1,8,9,14-16]$. Ultrasound is also the first chosen imaging modality in traumatology for the detection of trauma-associated lesions, known as focused assessment with sonography for trauma (FAST) [17].

Until nowadays, sonography has not been commonly used for the detection of free intra-abdominal air although the possibility of the detection of PP has been suggested in the literature $[1,5,18-20]$.

In the last few years, further development generated miniaturized ultrasound systems, leading to the introduction of hand-carried ultrasound (HCU) imagers. These HCU devices were initially developed for the military or air medical environment but have made their way into the daily clinical workflow [21 -23]. The major advantages of these devices are fast bedside availability and excellent transportability enabling prompt diagnosis and immediate therapeutic measures combined with low costs [24]. Additionally, the image quality of high-end ultrasound equipment has dramatically increased over the last few years resulting in better and faster high-resolution imaging of the whole abdomen.
Therefore, the aim of the study was the evaluation of the diagnostic yield of a new generation hand-carried ultrasound (HCU) imager and a high-end ultrasound (HUS) system in comparison to erect or left-lateral decubitus abdominal radiographs (AR) as well as to multidetector computed tomography (MDCT) as the standard of reference in patients with acute abdominal pain for the presence or absence of PP.

\section{Materials and Methods}

$\nabla$

\section{Design and Setting}

We prospectively included all consecutive patients who received an erect or left-lateral decubitus abdomen radiograph and a multidetector computed tomography because of acute abdominal pain in a period over one month in our department and for whom two experienced examiners performed the ultrasound examinations. To guarantee the presence of both examiners, only patients examined within the core service hours of the department of radiology, i. e. 8 am to $5 \mathrm{pm}$ on working days, were included in the study. All patients meeting these criteria were consecutively enrolled in this study irrespective of their underlying disease. The study was performed in a tertiary care university medical center. Study participant operators were neither aware of the indication for AR or MDCT nor of the underlying disease. During this period we were able to include a total of 31 patients. Their basic demographic data are reported in $\bullet$ Table 1.

Table 1 Basic demographic characteristics of enrolled patients

\begin{tabular}{lll} 
& number (No.) & percentage (\%) \\
\hline patients & 31 & 100 \\
\hline gender & 18 & 58 \\
male & 13 & 42 \\
female & $57(23-83)$ & \\
median age and age range (years) & $83(56-108)$ & \\
median weight and weight range & & \\
(kilograms) & & \\
underlying disease & 8 & 26 \\
inflammatory bowel disease & 6 & 19 \\
cholecystitis & 4 & 13 \\
diverticulitis & 4 & 13 \\
appendicitis & 3 & 9 \\
percutaneous endoscopic gastrostomy & 2 & 7 \\
mesenteric ischemia & 2 & 7 \\
renal colic & 1 & 3 \\
gastric perforation & 1 & 3 \\
myocardial infarction & & \\
& &
\end{tabular}




\section{Abdomen radiograph and multidetector computed tomography}

The indication for erect abdomen radiograph or left-lateral decubitus abdomen radiograph was acute abdominal pain in all $31 \mathrm{pa}-$ tients combined with the clinical suspicion of ileus in 13 cases and the clinical suspicion of hollow organ perforation in another 18 cases. All AR were acquired on a flat panel detector (Axiom Aristos Multix FDX, Siemens Healthcare AG, Erlangen, Germany). In these 31 patients an MDCT scan was acquired as well (128-slice CT, SOMATOM Definition Flash, Siemens Healthcare AG, Erlangen, Germany) for further diagnosis. The presence or absence of PP in AR and MDCT was diagnosed by an experienced board-certified radiologist with a specialization in abdominal imaging, who was blinded to the ultrasonographic and clinical findings.

\section{Abdominal ultrasound with hand-carried ultrasound device}

We employed a new generation state-of-the-art HCU device (VScan, GE Healthcare, Waukesha. WI, USA) with a plane 1.73.8 $\mathrm{MHz}$ transducer for two-dimensional imaging, a 3.5-inch screen and a total weight of $390 \mathrm{~g}$. The independent and experienced operator was a radiologist who had performed more than 1000 documented ultrasound examinations within 12 months under the supervision of an experienced ultrasound examiner who has conducted more than 5000 ultrasound examinations each year for more than 10 years. The operator was unaware of the findings of the clinical examination, HUS or AR. The examination with the hand-carried ultrasound imager was performed instantaneously before HUS yet before the acquisition of AR and MDCT.

Abdominal ultrasound with high-end ultrasound device Furthermore, abdominal ultrasound examination was performed with a high-end ultrasound system (LOGIQ E9, GE Healthcare, Waukesha. WI, USA) with a curved-array $1-5 \mathrm{MHz}$ transducer. The independent and experienced operator was a radiologist who has conducted more than 5000 ultrasound examinations each year for more than 10 years. The operator was unaware of the findings of the clinical examination, HCU or AR. The examination with the high-end ultrasound system was performed within a maximum of five minutes after $\mathrm{HCU}$ yet before the acquisition of AR and MDCT.

\section{Ultrasound technique}

To standardize and simplify the ultrasound examination, all patients were examined within a maximum of ten minutes before the acquisition of AR and MDCT. The mean scanning time was 1.5 minutes (range from 1 to 3 minutes) with HCU and HUS. The ultrasound examination was not intended to examine the complete abdomen, but was focused on detecting or excluding PP. The examination for free intra-abdominal air was carried out with patients in a supine and left-lateral position. The transducer was set parasagittally onto the right paramedian epigastric area in a supine position. Afterwards the transducer was set in the right mid-axillary line, rib-parallel in between the 8th and 10th intercostal space. These scans allowed the detection of PP by the recognition of strong reverberations as well as the shifting phenomenon and the enhancement of the peritoneal stripe $[19,20$, 25]. Diagnosis of PP was therefore made if a highly echoic area with a highly echoic tail and a mirror image in the ventral space of the liver could be detected [1]. Free intra-abdominal air must be differentiated from air in the lung, air in the gastrointestinal tract and subcutaneous emphysema [1].
Table 2 Scoring system concerning the quality and adaptability of the ultrasound images for the diagnosis of PP achieved with $\mathrm{HCU}$ and HUS. Decisive criterion is the glance at Morison's Pouch and the view of the costodiaphragmatic recess.

\begin{tabular}{|ll|}
\hline 5 & visible in an optimal way \\
\hline 4 & visible to the greatest possible extent \\
\hline 2 & visible to some extent \\
\hline 1 & visible to small extent, still utilizable for diagnosis \\
\hline 0 & not visible, not utilizable for diagnosis \\
\hline
\end{tabular}

\section{Quality of ultrasound images}

A simple scoring system concerning the quality and adaptability of the ultrasound images for the diagnosis of PP was employed for the ultrasound study. For the HCU and HUS device the best achievable image quality was scored from 0 (lowest quality) to 5 (best quality) by each operator. Scores of 0 and 1 were not suitable for a diagnostic decision of PP, whereas scores of 2, 3, 4 and 5 were considered as suitable. The different levels of this simple scoring system are outlined in 0 Table 2 . A decisive criterion is the glance at Morison's Pouch and the view of the costodiaphragmatic recess.

\section{Statistical analysis}

Data was acquired using Excel tables (Excel 2007, Microsoft, Redmond. WA, USA). Statistical analysis was performed using PASW (PASW V.18, IBM SPSS Inc., Armonk, NewYork, USA). Agreement between the findings of HCU and HUS with the diagnosis made by AR and MDCT as the standard of reference was assessed from $2 \times 2$ tables.

\section{Results}

\section{$\nabla$}

\section{Imaging quality}

Both HCU and HUS were technically feasible in all 31 patients. As mentioned before, the mean scanning time was 1.5 minutes (range from 1 to 3 minutes) with HCU and HUS.

In 29 of 31 cases $(94 \%)$ the image quality of the HUS device was rated 5 , in one case the score was 4 and in one another case the score was only 3.

The image quality of the HCU imager was rated 5 in 22 of 31 patients $(71 \%)$ and 4 in another 5 cases (16\%), whereas a score of 3 was given in the 4 remaining patients (13\%).

In summary all ultrasound images acquired using the $\mathrm{HCU}$ and HUS devices were suitable for diagnosis but the image quality was slightly lower for HCU compared to HUS.

\section{Diagnostic value}

The findings of AR and MDCT were congruent in all patients and PP was depicted in 5 of 31 patients, resulting in a prevalence of $16 \%$. Examination with HCU revealed PP correctly in 4 of 5 patients, but was false positive in 5 more patients. The absence of PP was correctly verified by HCU in 21 of 26 cases. Therefore, a sensitivity and specificity of $80 \%$ and $81 \%$ was calculated, respectively. In the one remaining patient HCU was false negative, the amount of free intra-abdominal air identified by AR and MDCT was minimal. The positive predictive value (PPV) and negative (NPV) predictive value for the diagnosis of PP with HCU were $44 \%$ and $95 \%$, respectively. 
Examination with HUS revealed PP correctly in 4 of 5 patients as well, and was false positive in 3 more patients. The absence of PP was correctly verified by HUS in 23 of 26 cases, but was also false negative in one more patient with a small amount of free intraabdominal air identified by AR and MDCT. Therefore, a sensitivity and a specificity of $80 \%$ and $89 \%$ were calculated, respectively. The PPV and NPV for the diagnosis of PP with HUS were $57 \%$ and $96 \%$, respectively.

The results of the diagnosis of PP by means of HCU and HUS are summarized in 0 Table 3.

The images presented in $\bullet$ Fig. 1 show congruent findings of HCU, HUS, AR and MDCT in the diagnosis of PP, whereas $\bullet$ Fig. 2 shows the finding of a Chilaiditi Syndrome in AR and MDCT which was mistaken for PP in HCU and HUS.

Table 3 Sensitivity, specificity, positive (PPV) and negative predictive value (NPV) for the diagnosis of PP using HCU and HUS with MDCT and AR as the standard of reference

\begin{tabular}{|l|l|}
\hline HCU & diagnosis of PP \\
\hline sensitivity & $80 \%$ \\
\hline specificity & $81 \%$ \\
\hline PPV & $44 \%$ \\
\hline NPV & $95 \%$ \\
\hline HUS & diagnosis of PP \\
\hline sensitivity & $80 \%$ \\
\hline specificity & $89 \%$ \\
\hline PPV & $57 \%$ \\
\hline NPV & $96 \%$ \\
\hline
\end{tabular}
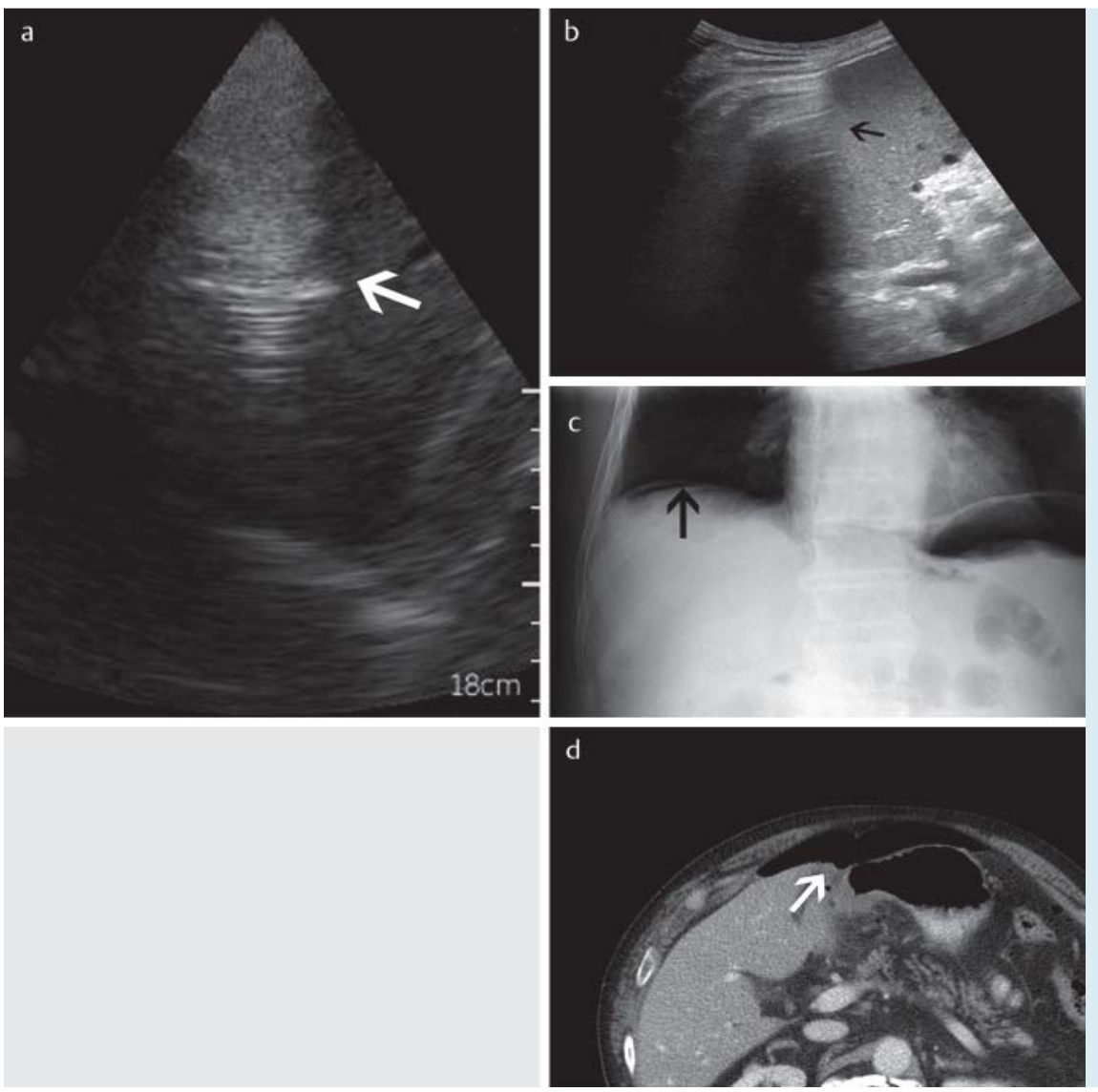

Fig. 1 For a 61-year-old male patient with acute abdominal pain, an erect abdomen radiograph was ordered by the ward physician under the suspicion of PP. Free intraabdominal air space was correctly diagnosed by HCU and HUS - a perforated gastric ulcer was diagnosed with MDCT and confirmed intraoperatively. a HCU B-mode image, showing free intraabdominal air space (marked with white arrow) b HUS B-mode image, showing free intraabdominal air space (marked with black arrow) c AR image, showing free intraabdominal air space (marked with black arrow) d MDCT scan, showing free intraabdominal air space (marked with white arrow)

Abb. 1 Bei einem 61-jährigen Mann wurde unter der Verdachtsdiagnose eines Pneumoperitoneum bei abdominellen Schmerzen eine konventionelle Abdomenübersichtsaufnahme angefertigt. Es wurde freie intraabdominelle Luft mittels HCU und HUS korrekt festgestellt. In der MDCT wurde schließlich ein perforiertes Magenulcus diagnostiziert, was sich intraoperativ bestätigte. a HCU BBild-Sonografie, freie intraabdominelle Luft markiert mittels weißem Pfeil b HUS B-Bild-Sonografie, freie intraabdominelle Luft markiert mittels schwarzem Pfeil c AR Bild, freie intraabdominelle Luft markiert mittels schwarzem Pfeil d MDCTScan, freie intraabdominelle Luft markiert mittels weißem Pfeil 


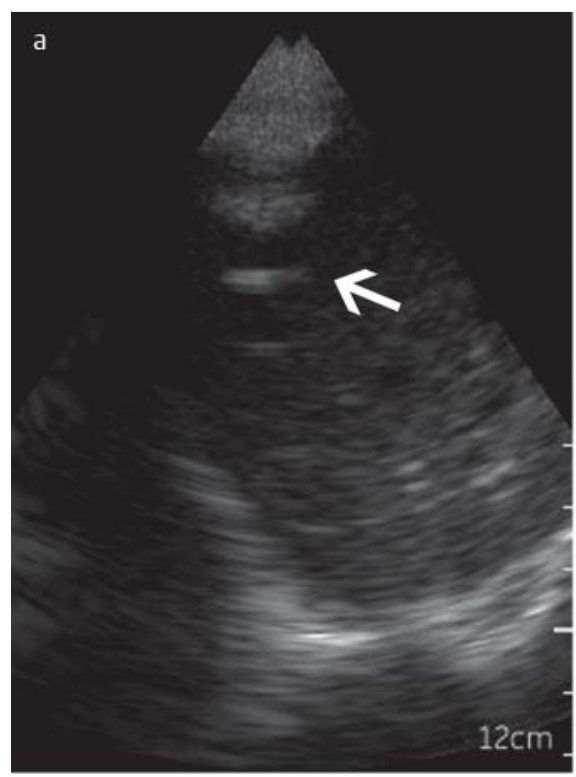

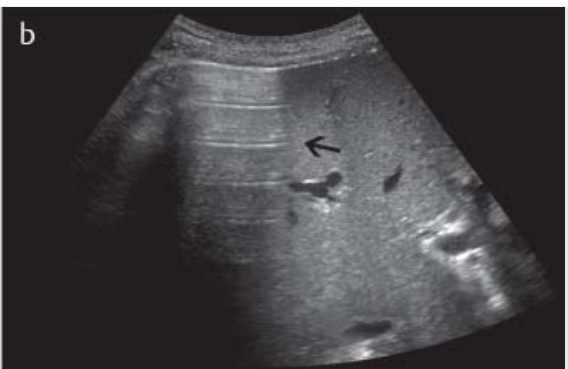
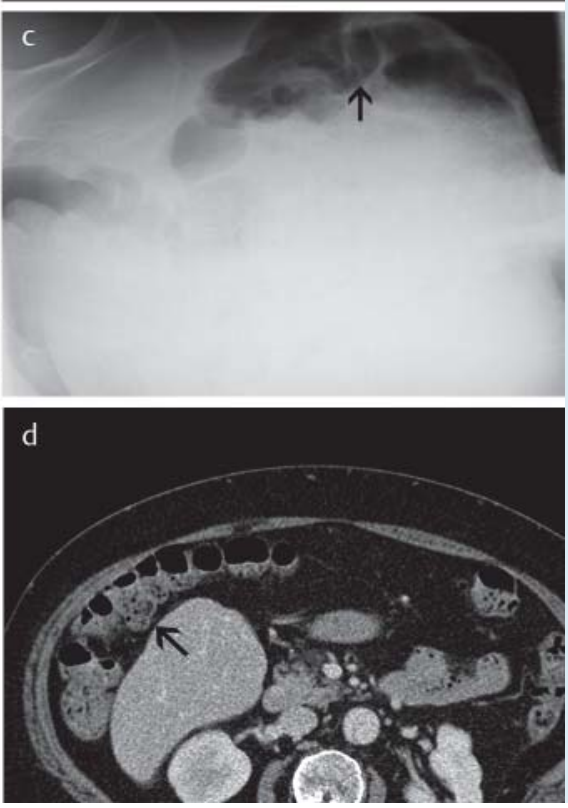

Fig. 2 For a 64-year-old male patient with acute abdominal pain, a left-lateral decubitus abdomen radiograph was ordered under the suspicion of ileus by the ward physician. A Chilaiditi Syndrome was correctly diagnosed by AR and MDCT, while HCU and HUS were false positive for the diagnosis of PP. a HCU B-mode image, the Chilaiditi Syndrome was misinterpreted as free intraabdominal air space (marked with white arrow) b HUS B-mode image, the Chilaiditi Syndrome was misinterpreted as free intraabdominal air space (marked with black arrow) c AR image, the Chilaiditi Syndrome can easily be diagnosed (marked with black arrow) d MDCT scan, the Chilaiditi Syndrome can easily be diagnosed (marked with black arrow).

Abb.2 Bei einem 64-jährigen Mann mit abdominellen Schmerzen wurde eine konventionelle Abdomenübersichtsaufnahme in Linksseitenlage zur Beurteilung eines lleus angefertigt. Mittels AR und MDCT wurde ein Chilaiditi-Syndrom erkannt, während mittels HCU und HUS fälschlicherweise freie intraabdmominelle Luft diagnostiziert wurde. a HCU-B-Bild-Sonografie, als freie intraabdominelle Luft fehlinterpretiertes Chilaiditi-Syndrom, markiert mittels weißem Pfeil b HUS-B-Bild-Sonografie, als freie intraabdominelle Luft fehlinterpretiertes Chilaiditi-Syndrom, markiert mittels schwarzem Pfeil c AR Bild, das Chilaiditi Syndrom kann leicht erkannt werden, markiert mittels schwarzem Pfeil d MDCTScan, das Chilaiditi-Syndrom kann leicht erkannt werden, markiert mittels schwarzem Pfeil.
Consequently, our results are inferior compared to the literature [18 - 20, 25]. HCU and HUS missed the correct diagnosis of PP in one case each and were false positive in 5 and 3 cases, respectively. Especially the high rate of false-positive cases is problematic as further investigations depend on the correct diagnosis of pneumoperitoneum and an unnecessary laparotomy could even be performed in false-positive cases.

Ultrasonography therefore seems to only be an ideal additional tool in immediate fast screening and as an initial examination because of its low costs and its ease of use for experienced operators. However, HCU and HUS can't compete with AR or MDCT for the diagnosis of PP, especially because of the high rate of false-positive results in the diagnosis of free intra-abdominal air.

There are some limitations of the present study. Only 31 patients were enrolled and only 5 cases of pneumoperitoneum were found. Furthermore, two different operators were working on either the hand-carried or the high-end ultrasound system and ultrasound examination is naturally an operator-dependent modality. Nevertheless the results of HCU and HUS were comparable. As pointed out before, ultrasonography is usually the first chosen imaging modality in patients with acute abdominal pain in emergency departments $[1,7-10,14,16,17]$. It can initially be employed because of its fast bedside availability and excellent transportability enabling prompt diagnosis and immediate therapeutic measures combined with low costs and the abandonment of radiation but ultrasonography has not been common for the detection of free intra-abdominal air which is coincident with our own findings $[20,28-30]$.

\section{Conclusion \\ $\nabla$}

In conclusion, examination with HCU and HUS for the presence or absence of PP can be used initially as a screening method in patients with acute abdominal pain and it can lead to a rapid extension of the diagnostic possibilities. However, it seems that an abdominal ultrasound examination performed with an HCU device or an HUS imager is inferior compared to the findings of AR and MDCT. Nevertheless HCU and HUS can accelerate the triage of patients and help to make decisions regarding the necessity of further exams without the need for radiation and while reducing economic and logistic resources.

\section{References}

1 Moriwaki Y, Sugiyama M, Toyoda H et al. Ultrasonography for the diagnosis of intraperitoneal free air in chest-abdominal-pelvic blunt trauma and critical acute abdominal pain. Arch Surg 2009; 144: 137-141 discussion 142

2 Miller RE, Nelson SW. The roentgenologic demonstration of tiny amounts of free intraperitoneal gas: experimental and clinical studies. Am J Roentgenol Radium Ther Nucl Med 1971; 112: 574 - 585

3 Levine MS. Plain film diagnosis of the acute abdomen. Emerg Med Clin North Am 1985; 3: 541 - 562

4 Seltzer SE. Abnormal intraabdominal gas collections visualized on computed tomography: a clinical and experimental study. Gastrointest Radiol 1984; 9: $127-131$

5 Braccini G, Lamacchia M, Boraschi P et al. Ultrasound versus plain film in the detection of pneumoperitoneum. Abdom Imaging 1996; 21: 404-412

6 Hoffstetter P, Schleder S, Jung EM et al. Konventionelle Abdomenübersichtsaufnahmen - welchen klinischen Nutzen hat die Aufnahme in Rückenlage? Dtsch Med Wochenschr 2011; 136: 2589-2593 
7 Rossi D, de Ville de Goyet J, Clement de Clety S et al. Management of intra-abdominal organ injury following blunt abdominal trauma in children. Intensive Care Med 1993; 19: 415-419

8 Huang MS, Liu M, Wu JK et al. Ultrasonography for the evaluation of hemoperitoneum during resuscitation: a simple scoring system. J Trauma 1994; 36: $173-177$

9 Lentz KA, McKenney MG, Nunez DB Jr et al. Evaluating blunt abdominal trauma:role for ultrasonography. J Ultrasound Med 1996; 15: 447 451

10 Hughes TM. The diagnosis of gastrointestinal tract injuries resulting from blunt trauma. Aust N Z J Surg 1999; 69: 770 - 777

11 Schleder S, Dendl LM, Ernstberger A et al. Diagnostic value of a handcarried ultrasound device for free intra-abdominal fluid and organ lacerations in major trauma patients. Emerg Med J 2013; 30: e20

12 Ko DR, Chung YE, Park I et al. Use of bedside sonography for diagnosing acute epiglottitis in the emergency department: a preliminary study. J Ultrasound Med 2012; 31: 19-22

13 Schuler A, Reuss J, Delorme S et al. Kosten von Ultraschalluntersuchungen im Krankenhaus - das Modell einer Deckungsbeitragsrechnung. Ultraschall in Med 2010; 31: 379-386

14 Chiquito PE. Blunt abdominal injuries. Diagnostic peritoneal lavage, ultrasonography and computed tomography scanning. Injury 1996; 27 : $117-124$

15 Moriwaki Y, Sugiyama M, Toyoda $H$ et al. Monitoring and evaluation of intraperitoneal bleeding (IPB) by small portable ultrasonography during transcatheter arterial embolization (TAE) in abdominal-pelvic trauma patients with shock: as a monitor for early detection of increase of IPB. Hepatogastroenterology 2006; 53: 175 - 178

16 Moriwaki Y, Sugiyama M, Fujita S et al. Application of ultrasonography for blunt laryngo-cervical-tracheal injury. J Trauma 2006; 61: $1156-$ 1161

17 Scalea TM, Rodriguez A, Chiu WC et al. Focused Assessment with Sonography for Trauma (FAST): results from an international consensus conference. J Trauma 1999; 46: 466-472

18 Lee DH, Lim JH, Ko YT et al. Sonographic detection of pneumoperitoneum in patients with acute abdomen. Am J Roentgenol Am J Roentgenol 1990; 154: 107-109
19 Muradali D, Wilson S, Burns PN et al. A specific sign of pneumoperitoneum on sonography: enhancement of the peritoneal stripe. Am J Roentgenol Am J Roentgenol 1999; 173: 1257-1262

20 Karahan OI, Kurt A, Yikilmaz A et al. New method for the detection of intraperitoneal free air by sonography: scissors maneuver. J Clin Ultrasound 2004; 32: $381-385$

21 Brooks AJ, Price V, Simms M. FAST on operational military deployment. Emerg Med J 2005; 22: 263-265

22 Kirkpatrick AW, Breeck K, Wong J et al. The potential of handheld trauma sonography in the air medical transport of the trauma victim. Air Med J 2005; 24: 34 - 39

23 Schleder S, Dornia C, Poschenrieder F et al. Bedside diagnosis of pleural effusion with a latest generation hand-carried ultrasound device in intensive care patients. Acta radiol 2012; 53: $556-560$

24 Schleder S, Dittmar M, Poschenrieder F et al. Diagnosis of pericardia effusion with a new generation hand-carried ultrasound device in cardiothoracic intensive care unit patients. Acta Radiol 2012; 53: $1133-1136$

25 Chang-Chien CS, Lin HH, Yen CL et al. Sonographic demonstration of free air in perforated peptic ulcers: comparison of sonography with radiography. J Clin Ultrasound 1989; 17: 95 - 100

26 Stapakis JC, Thickman D. Diagnosis of pneumoperitoneum: abdominal CT vs. upright chest film. J Comput Assist Tomogr 1992; 16: 713- 716

27 Marincek B. Nontraumatic abdominal emergencies: acute abdominal pain: diagnostic strategies. Eur Radiol 2002; 12: 2136-2150

28 Chen SC, Wang HP, Chen WJ et al. Selective use of ultrasonography for the detection of pneumoperitoneum. Acad Emerg Med 2002; 9: 643-645

29 Chen $\mathrm{CH}$, Yang CC, Yeh YH. Role of upright chest radiography and ultrasonography in demonstrating free air of perforated peptic ulcers. Hepatogastroenterology 2001; 48: 1082 - 1084

30 Chen SC, Yen ZS, Wang HP et al. Ultrasonography is superior to plain radiography in the diagnosis of pneumoperitoneum. Br J Surg 2002; 89: $351-354$ 